\title{
PERENCANAAN PEMBELAJARAN PPKN UNTUK MENINGKATKAN \\ MOTIVASI BELAJAR SISWA
}

${ }^{1}$ Lusiana Rahmatiani

${ }^{2}$ Tridays Repelita

11usiana.rahmatiani@ubpkarawang.ac.id

2tridays.repelita@ubpkarawang.ac.id

\begin{abstract}
This study aims to find out how to plan Civics learning by applying the inquiry model to increase students' learning motivation. This study uses a qualitative approach with a descriptive study method. The subjects of this study were students of SMP IT Gita Wirabangsa. Data collection techniques used interviews and observations to respondents at SMP IT Gita Wira Bangsa. The results of the study indicate that teachers plan well for Civics learning using the inquiry model to increase students' learning motivation and this can be seen in the lesson planning documents that have been made before the learning is carried out.
\end{abstract}

Keywords: Civic Lesson Planning, Inquiry Learning Model, learning motivation

\begin{abstract}
Abstrak
Penelitian ini bertujuan untuk mengetahui bagaimana merencanajan pembelajaran PPKn dengan menerapkan model inkuiri untuk meningkatkan motivasi belajar siswa. Penelitian ini menggunakan pendekatan kualitatif dengan metode studi deskriptif. Subjek penelitian ini adalah Siswa SMP IT Gita Wirabangsa. Teknik pengumpulan data menggunakan wawancara dan observasi kepada responden SMP IT Gita wira Bangsa. Hasil penelitian menunjukkan bahwa guru merencanakan dengan baik pembelajaran PPKn yang menggunakan model inkuiri untuk meningkatkan motivasi belajar siswa dan hal tersebut tampak pada dokumen perencanaan pembelajaran yang telah dibuat sebelum pembelajaran dilakukan.
\end{abstract}

Kata Kunci: Perencanaan Pembelajaran PPKn, Model Pembelajaran Inkuiri, Motivasi belajar

\section{Pendahuluan}

Merencanakan pembelajaran adalah hal yang wajib dilakukan oleh guru. Guru perlu membuat pembelajaran yang akan ia berikan kepada siswa harus sesuai dengan capaian pembelajaran tersebut. Proses pembelajaran harus menggunakan model, strategi dan media pembelajaran yang sesuai supaya menumbuhkan minat belajar siswa yang tinggi. Di dalam proses belajar mengajar, guru harus memiliki strategi dalam pembelajaran, agar siswa dapat belajar secara efektif dan efisien, mencapai pada tujuan yang diharapkan, salah satu langkah untuk memiliki strategi itu ialah harus menguasai teknik-teknik penyajian, atau disebut model mengajar. Model pembelajaran mempunyai peran yang sangat penting dalam kegiatan belajar mengajar, karena penggunaan model pembelajaran merupakan bagian yang harus mendapat perhatian guru dalam setiap kegiatan pembelajaran. Model yang 
digunakan untuk memecahkan suatu masalah yang dihadapi ataupun untuk menjawab suatu pertanyaan yang berbeda, dengan model yang digunakan untuk tujuan agar siswa mampu berpikir dan mengemukakan pendapatnya sendiri. Meningkatkan motivasi belajar siswa dalam proses pembelajaran tidaklah mudah, guru harus pandai merancang pembelajaran yang menarik agar siswa dapat termotivasi dan mampu mengikuti pembelajaran dengan baik. Penelitian ini bertujuan untuk memaparkan bagaimana guru PPKn merencanakan pembelajaran dengan menggunakan model inkuiri untuk meningkatkan motivasi belajar siswa.

\section{Metode Penelitian}

Pendekatan dalam penelitian ini menggunakan pendekatan kualitatif dengan metode studi deskriptif. Subjek dalam penelitian ini adalah 3 siswa, 1 guru mata pelajaran, dan 1 guru sebagai expert judgement SMP IT Gita Wirabangsa. Teknik pengumpulan data menggunakan observasi, wawancara dan dokumentasi. Keabsahan data menggunakan triangulasi sumber. Teknik analisis data dilakukan dengan tiga alur tahap kegiatan yaitu, reduksi data, penyajian data kemudian penarikan kesimpulan.

\section{Hasil dan pembahasan}

Untuk mendapat informasi mengenai perencanaan model inkuiri dalam pembelajaran PPKn untuk meningkatkan motivasi belajar siswa, peneliti menelaah wawancara hasilnya adalah sebagai berikut - Menurut FP, mengenai perencanaan model inkuiri ini sangatlah bagus sesuai dengan kurikulum 2013, meski dalam langkah perencanaanya bisa di katakan sedikit rumit ketika akan di terapkan dalam proses pembelajaran, karena dengan model ini guru masih di tuntut sebagai motivator, fasilitator, penanya (agar menyadarkan siswa dari kekeliruan yang mereka perbuat), dan administrator. Alasannya guru menggunakan model ini, selain sesuai dengan kurikulum 2013, model ini pula dapat mendidik siswa maupun siswi agar memiliki kemampuan, produktif, kreatif, inovatif, memotivasi siswa serta afektif dalam kegiatan belajar mengajar. Adapun dari segi persiapan untuk menerapkan model pembelajaran ini dengan memberitahukannya kepada siswa maupun siswi seminggu sebelum menerapkannya model pembelajaran ini. Lancarnya kegiatan belajar dengan model inkuiri ini tidak lain berjalan berkat dukungan yang bisa dikatakan cukup memadai sarana dan prasarana di Sekolah meski belum maksimal. Adapun kesulitan yang dihadapi dengan diterapkannya model inkuiri ini yaitu perlu ada nya proses penyesuaian terhadap materi, karena tidak semuanya materi bisa menggunakan modei ini.

Menurut YA, model inkuiri merupakan model yang mendukung dengan kurikulum 2013, karena model inkuiri membuat siswa maupun siswi untuk kreatif dan berfikir secara mendalam atau kritis. Perencanaan guru dalam menerapkan model inkuiri yaitu sudah sesuai dengan kurikulum 2013 dan RPP PPKn. Adapun berjalannya pembelajaran dengan diterapkannya model inkuiri dalam pembelajaran PPKn untuk meningkatkan motivasi belajar siswa, tidak terlepas dukungan kepala sekolah sebagai penerima kebijakan.

Menurut RI, perihal model inkuiri mereka mengetahui, karena guru menjelaskannya seminggu sebelum melakukan model tersebut. Jadi, saat guru memulainya kegiatan belajar mengajar, guru menyampaikan tujuan pembelajaran dan memaparkan materi akan berjalannya diskusi kelompok. Sedangkan menurut ENA, model inkuiri ini model pembelajaran yang sangat ia sukai, karena kelas terlihat aktif. Dan menurut AS, ia mengetahui model inkuiri ini, karena menurut pendapatnya, model ini bisa membawa dampak positif bagi dirinya yang mempunyai karakter tidak percaya diri, sampai sekarang ia berani untuk bertanya 
kepada guru saat ada materi yang ia tidak mengerti.

Tabel 1 Triangulasi Sumber

\section{Triangulasi Sumber}

\begin{tabular}{|c|c|c|}
\hline Guru & $\begin{array}{c}\text { Expert } \\
\text { Judgment }\end{array}$ & Siswa \\
\hline $\begin{array}{l}\text { Dilihat dari } \\
\text { pandangan }\end{array}$ & $\begin{array}{l}\text { Dilihat dari } \\
\text { pandangan }\end{array}$ & $\begin{array}{l}\text { Dilihat } \\
\text { dari }\end{array}$ \\
\hline $\begin{array}{l}\text { FP, dalam } \\
\text { perencanaan }\end{array}$ & $\begin{array}{l}\text { YA, dalam } \\
\text { perencanaan }\end{array}$ & $\begin{array}{l}\text { pandang } \\
\text { an RI, }\end{array}$ \\
\hline $\begin{array}{l}\text { untuk } \\
\text { menerapkan }\end{array}$ & $\begin{array}{l}\text { nya, yaitu } \\
\text { sudah sesuai }\end{array}$ & $\begin{array}{l}\text { ENA, } \\
\text { dan SA, }\end{array}$ \\
\hline model ini & dengan & saat guru \\
\hline bisa & kurikulum & memulai \\
\hline katakan & 2013 & kegiatan \\
\hline sedikit rumit & RPP PPKn. & belajar \\
\hline ketika akan & Adapun & mengajar \\
\hline di terapkan & berjalannya & \\
\hline dalam proses & pembelajaran & menyam \\
\hline pembelajaran & dengan & paikan \\
\hline , karena & diterapkanny & tujuan \\
\hline dengan & model & pembelaj \\
\hline model ini & inkuiri dalam & aran dan \\
\hline guru masih di & pembelajaran & memapar \\
\hline tuntut & PPKn untuk & kan \\
\hline sebagai & meningkatka & materi \\
\hline motivator, & $\mathrm{n} \quad$ motivasi & akan \\
\hline fasilitator, & belajar siswa, & berjalann \\
\hline penanya & tidak terlepas & ya \\
\hline (agar & dukungan & diskusi \\
\hline menyadarkan & kepala & kelompo \\
\hline siswa dari & sekolah & $\mathrm{k}$ dengan \\
\hline $\begin{array}{l}\text { kekeliruan } \\
\text { yang mereka }\end{array}$ & sebagai & $\begin{array}{l}\text { menggun } \\
\text { akan }\end{array}$ \\
\hline
\end{tabular}

$$
\begin{array}{lll}
\hline \text { perbuat), dan } & \text { penerima } & \text { model } \\
\text { administrator } & \text { kebijakan. } & \text { inqury } \\
& & \text { ini. }
\end{array}
$$

Pembelajaran

menurut

Winkel (1991) adalah

"seperangkat tindakan yang dirancang untuk mendukung proses belajar siswa, dengan memperhitungkan kejadiankejadian ekstrim yang berperanan terhadap rangkaian kejadian-kejadian yang intern yang berlangsung dialami siswa. Jadi, berdasarkan pendapat Winkel pembelajaran berawal dari kejadian-kejadian ekstrim yang terjadi dan dialami langsung oleh siswa itu sendiri".

Adapun pengertian model inkuiri menurut Mulyasa (2007), adalah "model yang mampu mengiring peserta didik untuk menyadari apa yang telah didapatkan selama belajar". Menurut Lahadisi (2014: 88) "Inkuiri berasal dari bahasa inggris "inquiri" secara harfiah berarti pertanyaan atau pemerikasaan, penyelidikan, maka di tegaskan bahwa inkuiri adalah the process of infestigating a problem (proses penyelidikan masalah) sedangkan secara terminologi inkuiri berarti proses berfikir kritis dan analisis untuk mencari dan menemukan sendiri jawaban dari satu masalah yang dipertanyakan".

Dengan kata lain inkuiri berkaitan dengan aktivitas dan keterampilan aktif yang fokus pada pencarian pengetahuan atau pengalaman untuk memuaskan rasa ingin tahu". Jadi, bisa dikatakan bahwa inkuiri merupakan proses penyelidikan masalah yang ada di lingkungan sekitar serta harus dianalisis secara kritis dan berkelompok. Maka bisa dikatakan inkuiri ialah yang berkaitan dengan aktivitas juga keterampilan yang berfokus pada pencarian pengetahuan serta pengalaman. 
Berkaitan dengan motivasi belajar, maka peneliti mengambil definisi menurut Setyowati (2007) yang juga model inkuiri ini merupakan "kebutuhan untuk mengembangkan kemampuan diri secara optimum, sehingga mampu berbuat yang lebih baik, berprestasi dan kreatif'.

\section{Kesimpulan dan Implikasi}

Kesimpulan yang dapat ditarik dari artikel ini adalah, guru PPKn mampu dengan baik dengan cara merumuskan tujuan pembelajaran, memilih pengalaman belajar untuk siswa, menentukan kegiatan belajar yang cocok, memilih bahan hingga evaluasi dan pengembangan pembelajaran selanjutnya. Guru memilih model inkuiri sebagai katalis untuk meningkatkan motivasi belajar siswa karena siswa akan ditempatkan pada sebuah kondisi yang baru dan mencari jawaban dari pengetahuannya secara mandiri.

\section{Daftar Pustaka}

Darmawati, J. (2013). Pengaruh Motivasi Belajar Dan Gaya Belajar Terhadap Prestasi Belajar Ekonomi Siswa SMA Negeri Di Kota Tuban. Tuban: Pendidikan Ekonomi. Vol 1. Hal 80.

Emda, A. (2017). Kedudukan Motivasi Belajar Siswa Dalam Pembelajaran. Banda Aceh: Pendidikan Tarbiyah. Vol 5. Hal 1.

Fitri, Saparayuningsih \& Agustriana. (2013). Perencanaan Pembelajaran Kurikulum 2013 Pendidikan Anak Usia Dini. Bengkulu: PAUD. Vol 2. Hal 3.

Heriawan, A., Darmajari \& Senjaya, A. (2007). Metodologi Pembelajaran. Banten: CV Iskandar.

Inah Nur Ety. (2015). Peran Komunikasi Dalam Interaksi Guru Dan Siswa.

Isjoni, H. (2013). Pembelajaran Kooperatif. Yogyakarta: Pustaka Belajar

Kaelan. (2013). Pendidikan Pancasila. Yogyakarta: Paradigma
Kendari: Fakultas Tarbiyah. Vol 8. Hal 152

Kendari: Tarbiyah. Vol 7. Hal 88-91.

Kosasih. (2016). Strategi Belajar dan Pembelajaran. Bandung: Yrama Widya

Lahadisi. (2014). Inkuiri Sebuah Strategi Menuju Pembelajaran Bermakna.

Nasution, K. M. (2017). Penggunaan Metode Pembelajaran Dalam Peningkatan Hasil Belajar Siswa. Serang Banten: Pendidikan Ilmu Tarbiyah. Vol 11. Hal 15.

Rahmatiani Lusiana. (2012). Pengaruh Pembelajaran Kooperatif Metode Student Team Achievement Division (STAD) dengan Peningkatan Pemahaman Siswa pada Mata Pelajaran PKn. Cimahi: PPKn

Ristawati. (2017). Pengaruh Media Pembelajaran Terhadap Motivasi Belajar Siswa. Makassar: Pend. Ilmu Sosial. Vol 2. Hal 158-159

Setyowati. (2007). Pengaruh Motivasi Belajar Terhadap Hasil Belajar. Semarang: Pend. Administrasi. Vol 5. Hal 14-16

Silvia. (2013). Implementasi Model Pembelajaran Example Non Example dalam Upaya Meningkatkan Motivasi Belajar Siswa pada Pembelajaran Pendidikan Kewarganegaraan. Bandung: Pendidikan Kewarganegaraan

Siregar dan Nara. (2017). Teori Belajar dan Pembelajaran. Bogor: Ghalia Indonesia

Sugiyono. (2017). Metodologi Penelitian. Bandung: Alfabeta

Sumantri Bambang. (2014). Peningkatan Kualitas Pembelajaran Pkn Melalui Model Pembelajaran Kooperatif Tipe Teams Game Tournamen (Tgt) Pada Siswa Kelas II Sd Negeri Pelem 2 Ngawi. Ngawi: PKn. Vol 13. Hal 24

Suprihatin Siti. (2015). Upaya Guru Dalam Meningkatkan Motivasi Belajar Siswa. Metro: Pendidikan Ekonomi.Vol 3. Hal 73-76. 
Susanto, E., \& Komalasari, K. (2015).

Pengaruh Pembelajaran, Habituasi

Dan Ekstrakurikuler Terhadap

Pembentukan Civic Disposition

Siswa Sma Negeri Se-Kota Bandar

Lampung. Jurnal Mimbar Demokrasi, 15(1).

Susanto, E., \& Saylendra, N. P. (2018).

Civic Education as Empowerment of

Civic Activism. Proceedings of the

Annual Civic Education Conference

(ACEC 2018).

https://doi.org/10.2991/acec-

18.2018.4

W.S.Winkel. (1991). Psikologi

Pengajaran. Jakarta: PAU-PPAI

Dirjen Dikti Depdikbud.

Wahyuni Arie. (2017). Analisis Hambatan

Belajar Mahasiswa Pada Mata

Kuliah Kalkulus Dasar. Semarang:

Pendidikan Matematika. Vol 1. Hal

6.

https://hildhaauliamaretha.wordpress.com/

2017/09/20/pendidikan-

kewarganegaraan/ [diakses pada 10

Mei 2018 Pukul 16:00]

https://dosenmuslim.com/pendidikan/indik

ator-indikator-motivasi-belajar/

[diakses pada 20 Desember 2018

Pukul 20:32] 